\title{
Mononuclear cell subsets and coronary artery lesions in Kawasaki disease
}

\author{
Susumu Furukawa, Tomoyo Matsubara, Keijiro Yabuta
}

\begin{abstract}
The peripheral blood mononuclear cell subsets in patients with Kawasaki disease and coronary artery lesions were investigated. Of the 106 patients 14 had lesions. Patients with Kawasaki disease and coronary artery lesions were found to have increased counts of CD14+ macrophages/monocytes compared with those of patients with Kawasaki disease without lesions. The absolute counts of CD14+ macrophages/monocytes form an important parameter to determine the severity of vascular damage during acute Kawasaki disease.
\end{abstract}

The immunological abnormalities observed in patients with Kawasaki disease are related to hyperreactive responses in immunocompetent cells because of the increased cytokine production $^{1-3}$ and expression of activated antigens on their cell surface. ${ }^{4}$ Several studies have reported on numerical changes of immunocompetent cells in patients with Kawasaki disease. ${ }^{6}$ However, there have been no reports concerning changes in patients with Kawasaki disease and coronary artery lesions as there are few patients with these lesions and Kawasaki disease. We investigated the peripheral blood mononuclear cell subsets in patients with Kawasaki disease and coronary artery lesions and compared the subsets counts with those of patients without lesions.

\section{Patients and methods}

Inclusion in this study depended on patients meeting the diagnostic criteria for Kawasaki disease. Sixty five boys and 41 girls were included; they were aged 1-68 months (mean 22 months). The day of onset of fever was recognised as the first day of illness. Blood samples were taken for analysis of peripheral blood mononuclear cell subsets between the third to the ninth days after onset of illness (mean (SD) $5 \cdot 8(1.6)$ days) before treatment by intravenous gammaglobulin and aspirin or aspirin alone. Patients received aspirin $30 \mathrm{mg} / \mathrm{kg} /$ day in three divided doses up until the 30th day after the onset of fever. Of the 106 patients with Kawasaki disease, 60 received the same course of aspirin and in addition received an infusion of intravenous gammaglobulin (Venilon, Teijin Limited, Tokyo) in a $5 \%$ solution at a daily dosage of $200 \mathrm{mg} / \mathrm{kg}$ for five consecutive days. Sixty seven of the 106 patients with Kawasaki disease were sampled for peripheral blood mononuclear cell subsets on the ninth to 15 th days (mean (SD), 11.5 (2.0) days) of illness, after treatment by intravenous gammaglobulin or during treatment by aspirin alone. Thirty six of the 67 patients with Kawasaki disease received aspirin and an infusion of intravenous gammaglobulin and the others received aspirin alone. In addition, 68 patients were examined for peripheral blood mononuclear cell subsets on the 20th to the 68th days (mean (SD) 33.9 (19.9) days) of illness during the convalescent stage. Two dimensional echocardiography was used to detect the presence of coronary artery lesions twice a week after admission. In accordance with the cardiovascular lesion diagnostic criteria in Kawasaki disease of the Research Committee on Kawasaki Disease coronary arteries with diameters of $4 \mathrm{~mm}$ or greater were regarded as exhibiting lesions. ${ }^{7}$ The control subjects were 22 healthy children aged 4-67 months (mean 26 months).

Using a method previously described, ${ }^{45}$ the percentage of the peripheral blood mononuclear cell subsets among mononuclear cells was assayed. The percentages of mononuclear cell subsets were assayed with a fluorescence activated cell sorter (FACS IV, Becton Dickson Immunocytometry Systems). For fluorescence procedures fluorescein isothiocyanate conjugated monoclonal antibodies used were as follows: CD3/Leu 4, CD4/Leu 3a, CD8/Leu 2a, CD57/Leu 7 (a natural killer cell and a part of T cell markers), CD19/Leu 12, or CD14/Leu M3 (Becton Dickinson Monoclonal Center). The mononuclear cell population was gated according to orthogonal scatter and forward scatter. Next, to exclude macrophages/monocytes from the analysis, the lymphocyte population was gated according to orthogonal scatter and forward scatter. From the ratio of peripheral blood mononuclear cells to white cell counts, the absolute counts of mononuclear cell subsets were calculated. Statistical analyses were performed using the Student's $t$ test.

\section{Results}

During a 30 day period after the onset of the disease, 14 patients were shown to have coronary artery lesions. Eight of these 14 patients received aspirin and an infusion of intravenous gammaglobulin and the others received aspirin alone.

Table 1 shows the absolute counts of white cells, mononuclear cells, lymphocytes, and mononuclear cell subsets during the acute stage before treatment and during the convalescent stage of Kawasaki disease together with control subjects. The absolute counts of CD14+ macrophages/monocytes and CD19+ B cells found in patients with Kawasaki disease were increased 
Table 1 Absolute counts of white cells, mononuclear cells, lymphocytes, and mononuclear cell subsets during the acute stage before treatment and during the convalescent stage of Kawasaki disease and of control subjects. All results for cell counts are expressed as $\times 10^{9} / l$ and mean $(S E M)$

\begin{tabular}{|c|c|c|c|c|c|}
\hline \multirow[b]{3}{*}{$\begin{array}{l}\text { Mean (SD) day sample taken } \\
\text { after onset of fever }\end{array}$} & \multirow{3}{*}{$\begin{array}{l}\text { Acute stage } \\
(n=106) \\
5.8(1.6)\end{array}$} & \multicolumn{2}{|c|}{ Coronary artery lesions } & \multirow{2}{*}{$\begin{array}{l}\text { Convalescent } \\
\text { stage }\end{array}$} & \multirow{2}{*}{$\begin{array}{l}\begin{array}{l}\text { Controls } \\
\text { subjects }\end{array} \\
(n=22)\end{array}$} \\
\hline & & $\begin{array}{l}\text { With } \\
(n=14)\end{array}$ & $\begin{array}{l}\text { Without } \\
(n=92)\end{array}$ & & \\
\hline & & $6 \cdot 1 \quad(1 \cdot 4)$ & $5 \cdot 7(1 \cdot 7)$ & $33.9(19.9)$ & \\
\hline White cells & $15 \cdot 59(0 \cdot 47)^{* *}$ & $16.94(1.07)$ & $15.38(0.52)$ & $8 \cdot 56(0 \cdot 29)$ & $8.41(0.39)$ \\
\hline Mononuclear cells & $4.58(0.21)$ & $4.86(0.79)$ & $4.54(0.21)$ & $5 \cdot 27(0 \cdot 20)$ & $4 \cdot 86(0.25)$ \\
\hline CD14+ macrophages/monocytes & $0.52(0.04)^{* * *}$ & $1.02(0.15)^{*}$ & $0.45(0.03)$ & $0.25(0.02)$ & $0.18(0.02)$ \\
\hline Lymphocytes & $4 \cdot 06(0 \cdot 20)$ & $3.85(0.69)$ & $4.09(0.20)$ & $4 \cdot 89(0 \cdot 19)$ & $4 \cdot 68(0 \cdot 25)$ \\
\hline \multicolumn{6}{|l|}{ Lymphocyte subsets: } \\
\hline CD3 $3+T$ cell & $2 \cdot 38(0 \cdot 14)$ & $2 \cdot 25(0 \cdot 43)$ & $2 \cdot 39(0 \cdot 14)$ & $3 \cdot 16(0 \cdot 14)$ & $2 \cdot 98(0 \cdot 24)$ \\
\hline $\mathrm{CD} 4+\mathrm{T}$ cell & $1.81(0.11)^{*}$ & $1.88(0.41)$ & $1.80(0.12)$ & $2 \cdot 27(0 \cdot 11)$ & $2 \cdot 33(0 \cdot 19)$ \\
\hline CD8 $+\mathrm{T}$ cell & $0.78(0.04)^{*}$ & $0.81(0.18)$ & $0.78(0.04)$ & $1.14(0.06)$ & $0.94(0.06)$ \\
\hline CD $57+$ cell & $0.24(0.02)^{*}$ & $0.30(0.09)$ & $0.23(0.02)$ & $0.58(0.07)$ & $0.35(0.06)$ \\
\hline CD19+ B cell & $1.23(0.09)^{*}$ & $1.78(0.48)$ & $1 \cdot 18(0.09)$ & $1.00(0.06)$ & $0.94(0.10)$ \\
\hline
\end{tabular}

:Significant at $\mathrm{p}<0.05 v$ control subjects; ${ }^{* *}$ significant at $\mathrm{p}<0.01 v$ control subjects; ${ }^{* *}$ significant at $\mathrm{p}<0.01 v$ Kawasaki disease without lesions.

during the acute stage preceding treatment compared with those found in control subjects $(\mathrm{p}<0.01$ and $\mathrm{p}<0.05$, respectively). The absolute counts of CD4+ and CD8 $+\mathrm{T}$ cells and CD57+ cells found in patients with Kawasaki disease decreased during the acute stage preceding treatment compared with those found in control subjects $(p<0.05)$. These increased absolute counts of CD14+ macrophages/monocytes and CD19+ B cells and decreased absolute counts of CD4+ and CD8+ $T$ cells, and CD57+ cells in patients with Kawasaki disease were seen to be within the normal range during the convalescent stage.

The absolute counts of CD14+ macrophages/ monocytes in patients with coronary artery lesions were higher than those of patients without lesions during the acute stage before treatment $(p<0.01)$. There were no significant differences in the absolute counts of $\mathrm{CD}_{3}+$, CD4+ and CD8+ T cells, CD57+ cells, and CD19+ $\mathrm{B}$ cells in patients with Kawasaki disease with and without lesions.

Eleven of the 14 patients with Kawasaki disease and lesions were examined for peripheral blood mononuclear cell subsets after treatment by intravenous gammaglobulin $(n=6)$ or during treatment by aspirin alone $(n=5)$. Table 2 shows the absolute counts of white cells and CD14+ marcophages/monocytes of patients with and without lesions after treatment by intravenous gammaglobulin or aspirin alone during the acute stage. The absolute counts of $\mathrm{CD} 14+$ macrophages/monocytes found in patients with coronary artery lesions were high during the acute stage after treatment by intravenous gammaglobulin or aspirin alone compared with those found in control subjects $(\mathrm{p}<0.02)$. Patients with Kawasaki disease without lesions, treated with aspirin alone, had high absolute counts of CD14+ macrophages/monocytes compared with control subjects and those treated with intravenous gammaglobulin $(p<0.01)$. There was no significant difference between the absolute counts of CD14+ macrophages/monocytes of patients without lesions treated with intravenous gammaglobulin and of control subjects.

\section{Discussion}

Treatment with intravenous gammaglobulin has been reported to be effective in reducing the incidence of coronary artery lesions in Kawasaki disease. ${ }^{8}$ Before the routine application of this treatment lesions developed in approximately $15 \%$ of patients with Kawasaki disease, ${ }^{9}$ while recently its incidence has decreased. Our study represents the first report on the determination of the numerical changes of immunocompetent cells in patients with Kawasaki disease and coronary artery lesions. Although several studies have been reported on the numerical changes of immunocompetent cells in patients with acute Kawasaki disease, those previous reports were based on the analysis of peripheral blood lymphocyte subsets. ${ }^{6}$ Here we analysed the peripheral blood mononuclear cell subsets including macrophages/monocytes in patients with Kawasaki disease with and without lesions.

The purpose of this study was to compare peripheral blood mononuclear cell subsets in patients with Kawasaki disease with and without coronary artery lesions, although we did not

Table 2 Absolute counts of white cells and CDI4+ macrophages/monocytes of patients with Kawasaki disease with and without coronary artery lesions after treatment by intravenous gammaglobulin (IVGG) or aspirin alone during the acute stage

\begin{tabular}{|c|c|c|c|c|}
\hline & $\begin{array}{l}\text { No of } \\
\text { patients }\end{array}$ & $\begin{array}{l}\text { Mean }(S D) \\
\text { dav of onset } \\
\text { of fever }\end{array}$ & $\begin{array}{l}\text { Mean (SEM) } \\
\text { white cells } \\
\left(\times 10^{\prime \prime} / l\right)\end{array}$ & $\begin{array}{l}\text { Mean (SEM) } \\
\text { CDI4+ macrophages/ } \\
\text { monocvtes }\left(\times 10^{\prime \prime} / l\right)\end{array}$ \\
\hline $\begin{array}{l}\text { With coronary artery lesions } \\
\text { Treated with aspirin } \\
\text { Treated with IVGG }\end{array}$ & $\begin{array}{r}11 \\
5 \\
6\end{array}$ & $\begin{array}{l}11 \cdot 5(2 \cdot 8) \\
11 \cdot 2(3 \cdot 0) \\
11 \cdot 7(2 \cdot 5)\end{array}$ & $\begin{array}{l}14 \cdot 34(2 \cdot 30) \\
11.01(1.82) \\
16.73(3.95)\end{array}$ & $\begin{array}{l}0.66(0 \cdot 16) \\
0.51(0 \cdot 20) \\
0.79(0 \cdot 25)\end{array}$ \\
\hline $\begin{array}{l}\text { Without coronary artery lesions } \\
\text { Treated with aspirin } \\
\text { Treated with IVGG }\end{array}$ & $\begin{array}{l}26 \\
30\end{array}$ & $\begin{array}{l}11.5(1.6) \\
11.7(2 \cdot 1)\end{array}$ & $\begin{array}{l}10.72(0.61) \\
10.37(0.75)\end{array}$ & $\begin{array}{l}0.35(0.04)^{2} \\
0.23(0.02)\end{array}$ \\
\hline
\end{tabular}

"Significant at $\mathbf{p}<0.05 v$ control subjects (table 1); significant at $\mathbf{p}<0.02 v$ control subjects (table 1); control subjects (table 1 ) and at $p<0.05 v$ treated with IVGG. 
include febrile controls in the present study. Patients with Kawasaki disease and lesions were found to have increased counts of CD14+ macrophages/monocytes compared with those of patients without lesions during the acute stage before and after treatment by intravenous gammaglobulin or aspirin alone. The absolute counts of CD14+ macrophages/monocytes in patients without lesions after treatment by intravenous gammaglobulin were lower than those in similar cases treated by aspirin alone. This result supports our previous finding that intravenous gammaglobulin treatment was effective for Kawasaki disease by reducing peripheral blood macrophages/monocytes. ${ }^{10}$ However, the absolute counts of CD14+ macrophages/monocytes found in patients with lesions were high during the acute stage after treatment by intravenous gammaglobulin compared with those found in control subjects. Our patients received intravenous gammaglobulin at a daily dosage of $200 \mathrm{mg} / \mathrm{kg}$ for five consecutive days as the Research Committee on Kawasaki Disease recommends a total dose of $1 \cdot 0 \mathrm{~g} / \mathrm{kg}$. ${ }^{11}$ Our results suggest that immunological activation in these patients persists after treatment with intravenous gammaglobulin and that higher doses may be needed. Further studies are needed in this area.

The macrophage/monocyte has been recognised as a tumour necrosis factor- $\alpha$ (TNF- $\alpha$ ), interleukin-1 (IL-1), and interleukin-6 (IL-6) producing cell in inflammatory and immunological reactions. It has been reported that the increased serum concentrations of TNF- $\alpha^{2}$ and IL- $6^{3}$ and secretion of IL-1 from mononuclear cells ${ }^{1}$ are more evident in patients with Kawasaki disease and coronary artery lesions than in patients without lesions during the acute stage. Our results suggest that the absolute counts of CD14+ macrophages/monocytes, together with these cytokines, form an important parameter to determine the severity of vascular damage during acute Kawasaki disease. Our results further suggest that the main characteristics of the pathogenesis of Kawasaki disease are increased numbers of peripheral blood macrophages/monocytes with the secretion of monokines by these activated cells. These immune responses develop more vigorously in patients with Kawasaki disease and coronary artery lesions.

The authors wish to thank Mr S Kuge for technical assistance This work was supported by a research grant (from 1983 to 1991) for the study of Kawasaki disease from the Ministry of Health and Welfare, Japan.

1 Leung DYM, Cotran RS, Kurt-Jones E, Burns JC, Newburger JW, Pober JS. Endothelial cell activation and high interleukin-1 secretion in the pathogenesis of acute Interleukin-1 secretion in the pathogen

2 Matsubara T, Furukawa S, Yabuta K. Serum levels of tumor necrosis factor, interleukin 2 receptor and gamma interferon necrosis factor, interleukin 2 receptor and gamma interferon in Kawasaki disease involved coronary

3 Furukawa S, Matsubara T, Yone K, Hirano Y, Okumura K, Yabuta K. Kawasaki disease differs from anaphylactoid purpura and measles with regard to tumor necrosis factor- $\alpha$ and interleukin 6 in serum. Eur $\mathcal{F}$ Pediatr 1992;151:44-7.

4 Furukawa S, Matsubara T, Motohashi T, Nakachi S, Sasai $K$, Yabuta $K$. Expression of FcER2/CD23 on peripheral blood macrophages/monocytes in Kawasaki disease. Clin Immunol Immunopathol 1990;56:280-6.

5 Furukawa S, Matsubara T, Tsuji K, Motohashi T, Okumura $\mathrm{K}$, Yabuta $\mathrm{K}$. Serum soluble CD4 and CD8 levels in Kawasaki disease. Clin Exp Immunol 1991;86:134-9.

6 Leung DYM, Burns JC, Newburger JW, Geha RS. Reversal of lymphocyte activation in vivo in the Kawasaki syndrome by intravenous gammaglobulin. I Clin Invest 1987;79. 468-72.

7 Research Committee on Kawasaki Disease. Report of subcommittee on standardization of diagnostic criteria and reporting of coronary artery lesions in Kawasaki disease
Ministry of Health and Welfare, 1984:56-66.

8 Furusho K, Kamiya T, Nakano H, et al. High-dose intravenous gammaglobulin for Kawasaki disease. Lancet 1984;ii: $1055-8$.

9 Kato H, Ichinose M, Yoshioka F, et al. Fate of coronary aneurysms in Kawasaki disease: serial coronary angiography and long-term follow-up study. Am $\mathcal{F}$ Cardiol 1982;49: $1759-66$.

10 Furukawa S, Matsubara T, Jujoh K, et al. Reduction of peripheral blood macrophages/monocytes in Kawasaki disease by intravenous gammaglobulin. Eur $\mathfrak{f}$ Pediat 1990;150:43-7.

11 Research Committee on Kawasaki Disease. Report on research concerning Kawasaki disease. Tokyo: Ministry of Health and Welfare, 1986:105-12 (in Japanese). 